\title{
A Case of Graves' Disease with Thymic Hyperplasia: The Response of the Thyroid Function, Thyrotropin Receptor Autoantibody, and Thymic Size to Thiamazole Treatment
}

\author{
Daichi Tsukada ${ }^{1}$, Katsumi Iizuka ${ }^{1-3}$, Ken Takao ${ }^{1}$, Yanyan Liu ${ }^{1}$, Sodai Kubota ${ }^{1,3}$, \\ Saki Okamoto-Kubota ${ }^{1,3}$, Teruaki Sakurai ${ }^{1}$, Toshinori Imaizumi ${ }^{1}$, Mayu Sakai ${ }^{1}$, \\ Takehiro Kato ${ }^{1}$, Masami Mizuno ${ }^{1}$, Takuo Hirota ${ }^{1}$, Tetsuya Suwa ${ }^{1}$, Yukio Horikawa ${ }^{1}$, \\ Mayumi Yamamoto ${ }^{4}$, Sumihisa Kubota ${ }^{5}$ and Daisuke Yabe ${ }^{1,3,6,7}$
}

\begin{abstract}
:
We treated a 22-year-old woman suffering from Graves' disease and thymic hyperplasia. She was referred to our institution for a close investigation of thyrotoxicosis and thymic mass. Thyroid tests and magnetic resonance imaging resulted in a diagnosis of Graves' disease and thymic hyperplasia. The thyroid function and thyroid-stimulating hormone receptor antibody (TRAb) were normalized one and five months after thiamazole initiation, respectively. The thymic size began to decrease after 1 month and was further decreased after 5 months; it was normalized after 12 months. The correlation between TRAb titers and the thymic size (R ${ }^{2}=0.99$ ) suggested that the patient's autoimmunity might have contributed to the thymic hyperplasia.
\end{abstract}

Key words: Graves' disease, thymic hyperplasia, soluble Interleukin-2 Receptor, sIL2R

(Intern Med Advance Publication)

(DOI: 10.2169/internalmedicine.8710-21)

\section{Introduction}

Thymic hyperplasia is frequently found in patients with Graves' disease $(1,2)$. However, the complete mechanism underlying the development of thymic hyperplasia in patients with Graves' disease remains unclear, partly because chest computed tomography (CT) is not regularly performed in such patients. Normalization of the thyroid function in Graves' disease reportedly reduces the thymic size (3), suggesting that thymic resection may be unnecessary in Graves' disease with thymic hyperplasia (4). Although there are some reports documenting changes in the thymic size and thyroid function $(5,6)$, differences following thiamazole treatment compared with pre-treatment are mainly described.

In the etiology of anterior mediastinal mass, the differential diagnosis between malignant lymphoma and thymic hyperplasia is important. Plasma levels of sIL-2R, a tumor marker for malignant lymphoma, are also increased in thyrotoxicosis and normalized by treatment for hyperthyroidism $(7,8)$. Therefore, we postulated that if anterior mediastinal masses were thymic hyperplasia, the plasma sIL-2R levels and thymic size would be normalized in response to the treatment of Graves' disease.

We recently treated a case of Graves' disease with thymic hyperplasia in which we quantified changes in the thyroid function, thyrotropin receptor autoantibody (TRAb) levels and thymic size estimated based on CT findings as well as

${ }^{1}$ Department of Diabetes, Endocrinology and Metabolism/Department of Rheumatology and Clinical Immunology, Gifu University Graduate School of Medicine, Gifu University Graduate School of Medicine, Japan, ${ }^{2}$ Department of Clinical Nutrition, Fujita Health University, Japan, ${ }^{3}$ Yutaka Seino Distinguished Center for Diabetes Research, Kansai Electric Power Medical Research Institution, Japan, ${ }^{4}$ Health Administration Center, Gifu University, Japan, ${ }^{5}$ Kubota Thyroid Clinic, Japan, ${ }^{6}$ Division of Molecular and Metabolic Medicine, Department of Physiology and Cell Biology, Kobe University Graduate School of Medicine, Japan and ${ }^{7}$ Center for Healthcare Information Technology, Tokai National Higher Education and Research System, Japan

Received: September 23, 2021; Accepted: January 4, 2022; Advance Publication by J-STAGE: February 26, 2022

Correspondence to Dr. Katsumi Iizuka, katsumi.iizuka@fujita-hu.ac.jp 
Table. Urinalysis, Blood Count, Biochemistry and Thyroid-related Items in the Patient.

\begin{tabular}{|c|c|c|c|c|c|}
\hline Urinalysis & & Biochemistry & & LDL-c (mg/dL) & $83(65-140)$ \\
\hline Specific gravity & 1.016 & $\mathrm{TP}(\mathrm{g} / \mathrm{dL})$ & $7.2(6.6-8.1)$ & Triglycerides (mg/dL) & $179(30-150)$ \\
\hline Protein & - & Albumin (g/dL) & $4.4(4.1-5.1)$ & HDL-c (mg/dL) & $44(30-150)$ \\
\hline Glucose & - & $\operatorname{AST}(\mathrm{U} / \mathrm{L})$ & $22(13-30)$ & Glucose $(\mathrm{mg} / \mathrm{dL})$ & $113(73-109)$ \\
\hline Hemoglobin & - & ALT (U/L) & $29(7-23)$ & HbA1c $(\%)$ & $5.6(4.9-6.0)$ \\
\hline Ketone & - & LDH (U/L) & $172(124-222)$ & Thyroid-related items & \\
\hline Blood counts & & $\operatorname{ALP}(\mathrm{U} / \mathrm{L})$ & $596(106-322)$ & $\mathrm{TSH}(\mu \mathrm{IU} / \mathrm{mL})$ & $<0.02(0.54-4.26)$ \\
\hline $\mathrm{WBC}\left(\times 10^{3} / \mu \mathrm{L}\right)$ & $4.96(3.3-8.6)$ & $\gamma \mathrm{GTP}(\mathrm{U} / \mathrm{L})$ & $26(9-32)$ & Free $T_{4}(\mathrm{ng} / \mathrm{dL})$ & $7.37(0.76-1.65)$ \\
\hline $\mathrm{RBC}\left(\times 10^{6} / \mu \mathrm{L}\right)$ & $5.26(3.86-4.92)$ & Creatinine (mg/dL) & $0.49(0.46-0.79)$ & Free $T_{3}(\mathrm{pg} / \mathrm{mL})$ & $25.89(2.39-4.06)$ \\
\hline $\mathrm{Hb}(\mathrm{g} / \mathrm{dL})$ & $13.4(13.7-16.8)$ & Uric acid (mg/dL) & $6.6(2.6-7.0)$ & $\mathrm{TRAb}(\%)$ & $41.3(<15)$ \\
\hline $\mathrm{Ht}(\%)$ & $40.3(40.7-50.1)$ & $\mathrm{Na}^{+}(\mathrm{mEq} / \mathrm{L})$ & $142(138-145)$ & $\operatorname{Tg} \mathrm{Ab}(\mathrm{IU} / \mathrm{mL})$ & $78(<28)$ \\
\hline MCV (fL) & $76.6(83.6-98.2)$ & $\mathrm{K}^{+}(\mathrm{mEq} / \mathrm{L})$ & $4.2(3.6-4.8)$ & $\mathrm{TPO} \mathrm{Ab}(\mathrm{IU} / \mathrm{mL})$ & $153(<3.3)$ \\
\hline $\mathrm{MCHC}(\%)$ & $25.5(31.7-35.3)$ & $\mathrm{Cl}^{-}(\mathrm{mEq} / \mathrm{L})$ & $107(101-108)$ & $\operatorname{Tg}(\mathrm{ng} / \mathrm{mL})$ & $217(5.0-30.0)$ \\
\hline \multirow[t]{2}{*}{ Platelets $\left(\times 10^{4} / \mu \mathrm{L}\right)$} & $33.3(15.8-34.8)$ & $\mathrm{Ca}^{2+}(\mathrm{mg} / \mathrm{dL})$ & $9.9(8.8-10.1)$ & & \\
\hline & & $\mathrm{Pi}^{2-}(\mathrm{mg} / \mathrm{dL})$ & $4.3(2.7-4.6)$ & & \\
\hline
\end{tabular}

ALP: alkaline phosphatase, AST: aspartate aminotransferase, ALT: alanine aminotransferase, Hb: hemoglobin, Ht: hematocrit, $\gamma$ GTP: $\gamma$-glutamyltransferase, LDH: lactate dehydrogenase, MCHC: mean corpuscular hemoglobin concentration, MCV: mean corpuscular volume, RBC: red blood cells, TP: toral protein, TRAb: thyroid stimulating hormone receptor autoantibody, TSH: thyroid-stimulating hormone, WBC: white blood cells, Tg: thyroglobulin, TPO: thyroid peroxidase

soluble interleukin-2 receptor (sIL-2R) levels.

\section{Case Report}

A 22-year-old woman was admitted to a neighboring hospital due to headache, palpitations and chest pain over the previous six months. She was suspected of having thyrotoxicosis based on her symptoms and was referred to our institution for a further investigation along with an examination of a solid anterior mediastinal thymic mass without infiltration of surrounding structures that was detected by chest CT.

Upon admission, her thyroid-stimulating hormone (TSH) levels were suppressed $(<0.02 \mu \mathrm{U} / \mathrm{mL})$ (Normal range, 0.54$4.26 \mu \mathrm{U} / \mathrm{mL}$; Eclusys TSH (S300); Roche, Tokyo, Japan), and the levels of free $\mathrm{T}_{3}$ and free $\mathrm{T}_{4}$ were $25.89 \mathrm{pg} / \mathrm{mL}$ (Normal range, 2.39-4.06 pg/mL; Eclusys $\mathrm{FT}_{3}$ III (S300); Roche) and $7.37 \mathrm{ng} / \mathrm{dL}$ (Normal range, 0.76-1.65 ng/dL; Eclusys $\mathrm{FT}_{4}$ III (S300); Roche), respectively (Table). The evaluation of TSH, free $\mathrm{T}_{3}$ and free $\mathrm{T}_{4}$ is based on an electrochemiluminescence immunoassay. Her TRAb titer was $41.3 \%$ (Normal range, <15 \%; TRAb Cosmic III; Cosmic Corporation, Tokyo, Japan) (Table). The PEG-based TRAb titer assays were expressed as the percentage inhibition of ${ }^{125}$ I-TSH binding to TSH receptors.

Ultrasonography revealed diffuse thyroid enlargement along with an increased vascular flow, which is compatible with Graves' disease. Her scintigram showed an increased thyroid uptake of technetium-99m-pertechnetate, which is also consistent with Graves' disease. Her sIL-2R was relatively high (1,403 Um/L; Normal range, 122-496 Um/L; Sekisui Medical, Tokyo, Japan) (Fig. 1). However, magnetic resonance imaging (MRI) showed the accumulation of fat in the thymus, ruling out malignant lymphoma and thymoma and further suggesting thymic hyperplasia.

One month after the initiation of thiamazole $(20 \mathrm{mg}$ per day), her hyperthyroid-related symptoms (e.g. dyspnea and tachycardia) disappeared and levels of free $\mathrm{T}_{4}$ and $\mathrm{T}_{3}$ were normalized (Fig. 1). Two months after thiamazole initiation, sIL-2R was also normalized; 4 months after thiamazole initiation, her TRAb titer and TSH levels were normalized (Fig. 1). We also compared the average area $\left(\mathrm{mm}^{2}\right)$ and density (HU) among the three continuous slices of the lower end of the tracheal bifurcation. A low CT density indicates a shift from thymic hyperplasia to adipose tissues. The thymus areas and density on CT started to decrease from one month after treatment initiation and were further decreased by five months after thiamazole initiation; they had almost normalized after 12 months (Fig. 1, 2). During the observation period, no myasthenia gravis-related symptoms were seen, nor was any acetylcholine receptor autoantibody detected (AchR $\leq 0.20 \mathrm{nmol} / \mathrm{L})$.

\section{Discussion}

We treated a case of Graves' disease with thymic hyperplasia that was diminished in response to thiamazole treatment. Interestingly, the thymic size started to decrease as early as one month after the treatment of Graves' disease had started.

Michie and Gunn reported that approximately 38\% of patients with thyrotoxicosis show histologic changes of the thymus gland (1). However, the mechanisms causing thymic hyperplasia in Graves' disease remain largely unknown. Thymic hyperplasia in Graves' disease includes two subtypes: true hyperplasia and thymic lymphoid hyperplasia (9-15). It was reported that $77 \%$ (10 in 13 cases) had lymphoid follicles, and the remaining $23 \%$ (3 in 13 cases) were diagnosed with true thymic hyperplasia in thymic tissues of Graves' disease (11). Furthermore, a case of combined true thymic hyperplasia and lymphoid hyperplasia in 


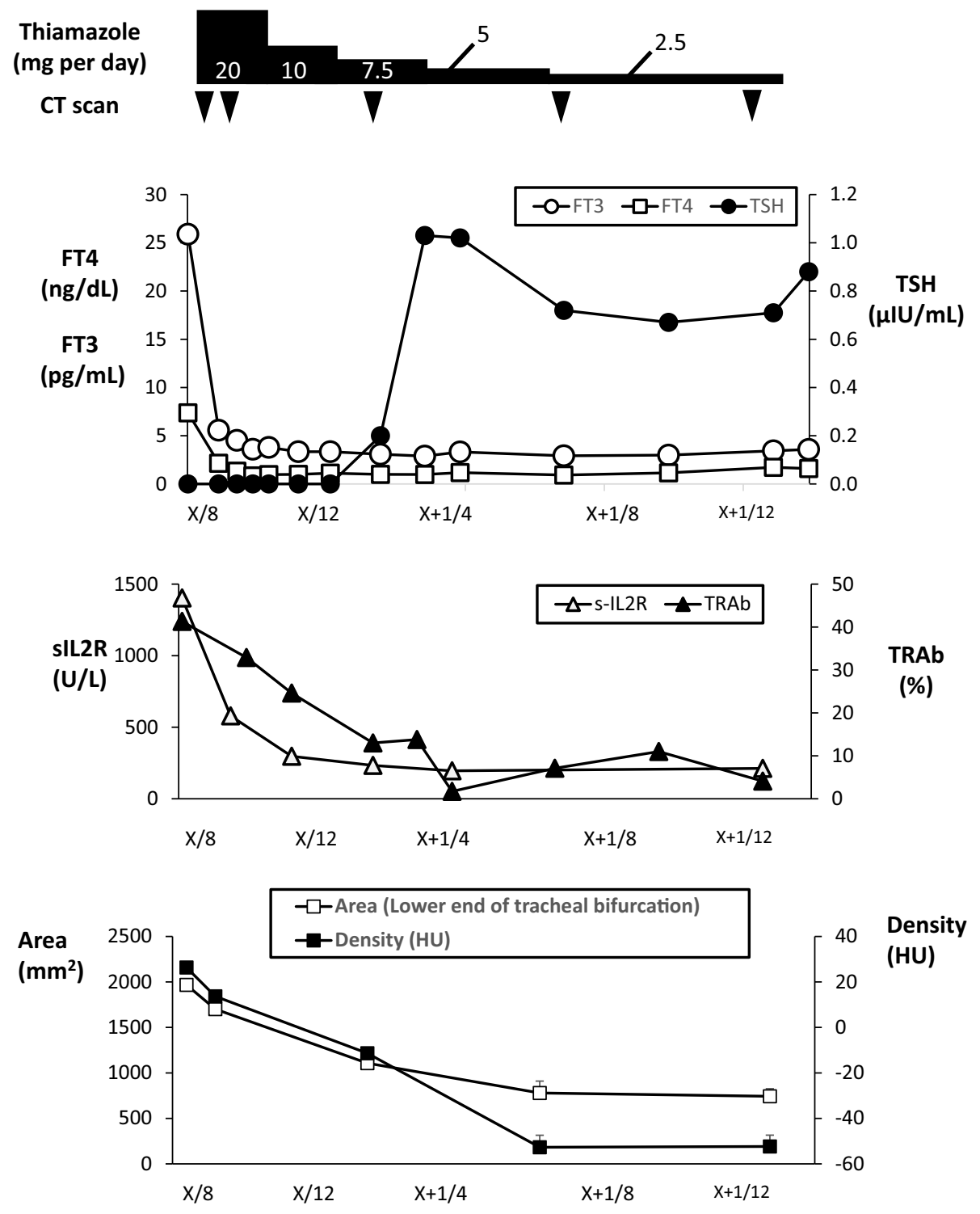

Figure 1. Changes in thyroid hormones, free T3 (open circle) and free T4 (open square), thyroidstimulating hormone (TSH) (closed circle), and TSH receptor autoantibody (TRAb) titers (closed triangle), soluble interleukin-2 receptors (sIL-2R) (open triangle), and average thymic area (open square) and density (closed square) in the lower end of the tracheal bifurcation. CT: computed tomography

Graves' disease has also been reported (13). True thymic hyperplasia occurs due to an increase in the number of thymic epithelial cells. This form of thymic hyperplasia is particularly prevalent among children and young patients and is not associated with autoimmune diseases (9).

It has been reported that $\mathrm{TSH}$ receptors are expressed in the human thymus and that their activation may induce proliferation of thymic epithelial cells (16). However, some investigators have reported that thyroid hormones directly stimulate thymic cell proliferation, and the effects of T3 on thymic cells proliferation are much stronger than those of TRAb $(15,17,18)$. In contrast, thymic lymphoid hyperplasia is due to hyperplastic lymph follicles within the thymus and is associated with autoimmune diseases (15). A histological analysis is the only method that can differentiate true and lymphoid hyperplasia, so we were unable to distinguish lymphoid hyperplasia from true hyperplasia based on CT findings (19). In the present patient, the thyroid hormone levels had nearly normalized as early as one month after the initiation of thiamazole, although the thymic size gradually decreased with the decline in TRAb titers. Titers of TRAb reflect the severity of autoimmunity, and TRAb itself might also promote thymic cell hyperplasia weakly $(15,17)$. The significant correlation between TRAb titers and thymic size $\left(\mathrm{R}^{2}=0.99\right)$ suggested that our patient's autoimmunity might have caused lymphoid hyperplasia, rather than true hyperplasia (Fig. 1), although it is difficult to rule out the possibility of true thymic hyperplasia without performing a histological analysis.

Another noteworthy clinical characteristic of our patient was her high sIL-2R levels, levels, which were attenuated after the initiation of thiamazole treatment (Fig. 1). IL-2 and 


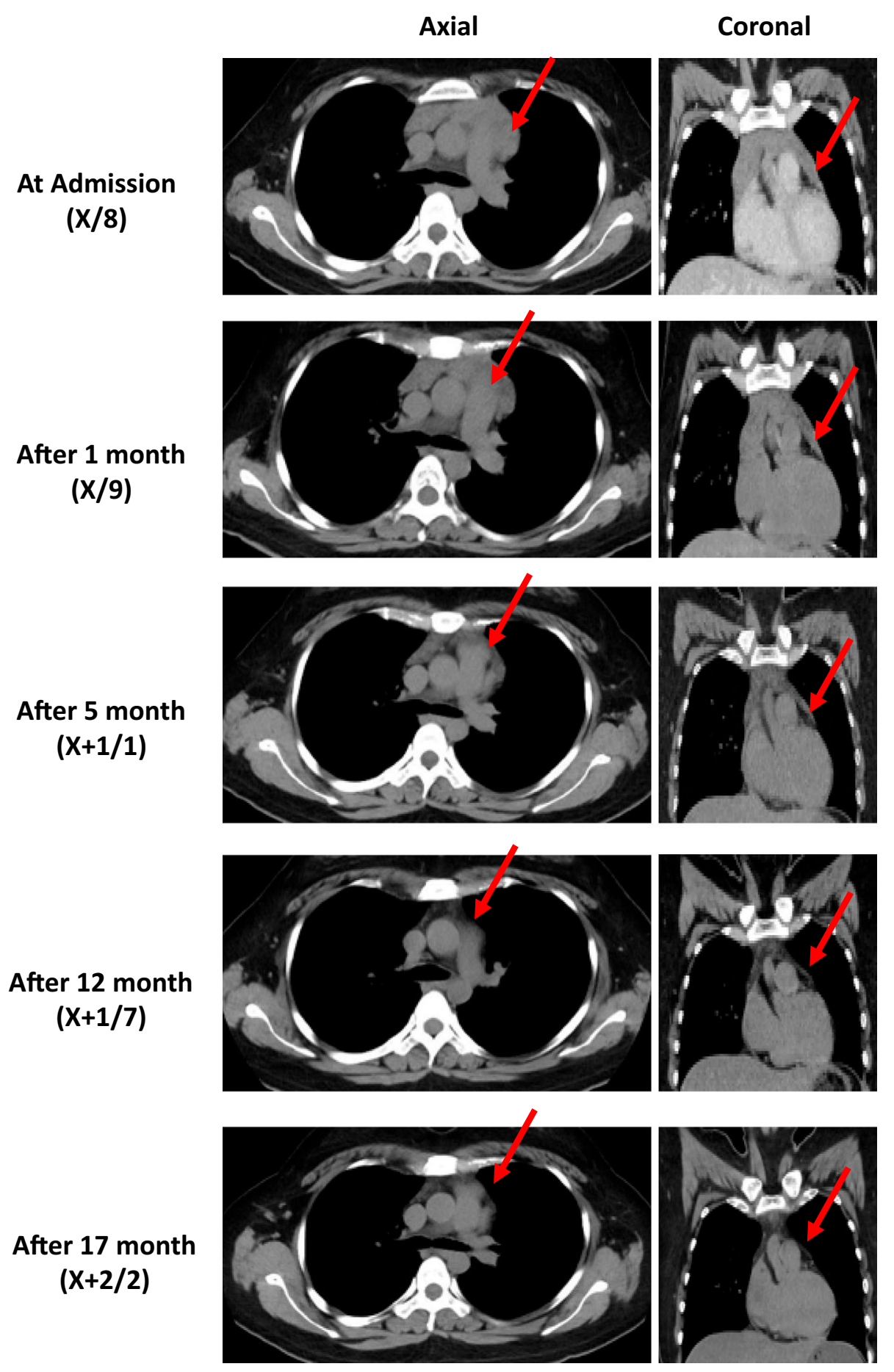

Figure 2. Changes in the thymic volume. Axial and coronal images. Red arrows indicate the thymus.

its receptor have critical roles in essential functions of the immune system, primarily via their direct effects on $\mathrm{T}$ lymphocytes (7). While the physiological role of sIL-2R remains unclear, it has been reported that sIL-2R levels are enhanced by thyroid hormones $(8,20,21)$. These findings may support the differential diagnosis of thymic hyperplasia and malignant lymphoma or thymoma in patients with Graves' disease, allowing unnecessary surgery to be avoided. These findings, along with the response of thymic hyperplasia to thiamazole, suggest that careful follow-up of changes in the thymic size and sIL-2R levels may contribute to the differential diagnosis of malignant lymphoma and thymic hyperplasia.

In conclusion, we treated a case of Graves' disease with thymic hyperplasia in which the responses of the thyroid hormones, TRAb and thymic size in response to thiamazole treatment suggested a close relationship between thymic hyperplasia and Graves' disease.

The authors state that they have no Conflict of Interest (COI).

Acknowledgement 
The authors are grateful to the patient for her contribution to this study. The authors also thank J. Kawada, H. Tsuchida and M. Kato for their technical assistance and M. Yato, Y. Ogiso and M. Nozu for their secretarial assistance.

\section{Funding}

None.

\section{Authorship}

All named authors meet the International Committee of Medical Journal Editors (ICMJE) criteria for authorship for this article, take responsibility for the integrity of the work as a whole and have given their approval for this version to be published.

\section{Disclosures}

None of the authors have potential conflicts of interest associated with this research.

\section{Compliance with ethical guidelines}

All procedures performed in studies involving human participants followed the 1964 Declaration of Helsinki and its later amendments or comparable ethical standards. Informed consent was obtained from the patient.

\section{References}

1. Gunn A, Michie W, Irvine WJ. The thymus in thyroid disease Lancet 10: 76-78, 1964.

2. Popoveniuc G, Sharma M, Devdhar M, et al. Graves' disease and thymic hyperplasia: the relationship of thymic volume to thyroid function. Thyroid 20: 1015-1018, 2010.

3. Haider U, Richards P, Gianoukakis AG. Thymic Hyperplasia Associated with Graves' Disease: Pathophysiology and Proposed Management Algorithm. Thyroid 27: 994-1000, 2017.

4. Inoue K, Sugio K, Inoue T, et al. Hyperplasia of the thymic gland in a patient with Graves' disease. Ann Thorac Cardiovasc Surg 6: 397-400, 2000.

5. Voss M, Saeed ZI, Donegan D. Not a Grave Finding: Thymic Hyperplasia in the Setting of Graves' Disease. Am J Med 133: 308310, 2020.

6. Wan W, Colburn JA. Massive thymic hyperplasia secondary to Graves' disease. AACE Clin Case Rep 6: e144-e146, 2020.

7. Damoiseaux J. The IL-2 - IL-2 receptor pathway in health and disease: The role of the soluble IL-2 receptor. Clin Immunol 218:
108515, 2020.

8. Smallridge RC, Tsokos GC, Burman KD, et al. Soluble interleukin-2 receptor is a thyroid hormone-dependent earlyresponse marker in the treatment of thyrotoxicosis. Clin Diagn Lab Immunol 4: 583-586, 1997.

9. Ricci C, Pescarmona E, Rendina EA, et al. True thymic hyperplasia: a clinicopathological study. Ann Thorac Surg 47: 741-745, 1989.

10. Zhang $\mathrm{K}, \mathrm{Wu} \mathrm{W}, \mathrm{Wu} \mathrm{Y}$, et al. Thymic lymphoid hyperplasia with Graves' disease in a 28-year-old female: a case report. Gland Surg 9: 437-441, 2020.

11. Michie W, Gunn A. The thyroid, the thymus and autoimmunity. $\mathrm{Br}$ J Clin Pract 20: 9-13, 1966.

12. Kotwal N, Singh Y, Menon A, et al. Thymic hyperplasia in Graves' disease. Indian J Endocrinol Metab 17: 521-523, 2013.

13. Judd R, Bueso-Ramos C. Combined true thymic hyperplasia and lymphoid hyperplasia in Graves' disease. Pediatr Pathol 10: 829836, 1990.

14. Le Panse R, Bismuth J, Cizeron-Clairac G, et al. Thymic remodeling associated with hyperplasia in myasthenia gravis. Autoimmunity 43: 401-412, 2010.

15. Dalla Costa M, Mangano FA, Betterle C. Thymic hyperplasia in patients with Graves' disease. J Endocrinol Invest 37: 1175-1179, 2014.

16. Murakami M, Hosoi Y, Negishi T, et al. Thymic hyperplasia in patients with Graves' disease. Identification of thyrotropin receptors in human thymus. J Clin Invest 98: 2228-2234, 1996.

17. Scheiff JM, Cordier AC, Haumont S. Epithelial cell proliferation in thymic hyperplasia induced by triiodothyronine. Clin Exp Immunol 27: 516-521, 1977.

18. Jinguji M, Nakajo M, Nakajo M, et al. Thymic involution after radioiodine therapy for Graves disease: relationships with serum thyroid hormones and TRAb. J Endocr Soc 1: 852-860, 2017.

19. Mendelson DS. Imaging of the thymus. Chest Surg Clin N Am 11: 269-293, 2001.

20. Mariotti S, Caturegli P, Barbesino G, et al. Thyroid function and thyroid autoimmunity independently modulate serum concentration of soluble interleukin 2 (IL-2) receptor (sIL-2R) in thyroid diseases. Clin Endocrinol (Oxf) 3: 415-422, 1992.

21. Shimoda Y, Satoh T, Takahashi H, et al. A case of thyroid storm with a markedly elevated level of circulating soluble interleukin-2 receptor complicated by multiple organ failure and disseminated intravascular coagulation syndrome. Endocr J 61: 691-696, 2014.

The Internal Medicine is an Open Access journal distributed under the Creative Commons Attribution-NonCommercial-NoDerivatives 4.0 International License. To view the details of this license, please visit (https://creativecommons.org/licenses/ by-nc-nd/4.0/).

\section{(C) The Japanese Society of Internal Medicine Intern Med Advance Publication}

